\title{
FT-RAMAN methodology for the monitoring of honeys' spirit distillation process
}

\author{
Ofélia Anjos $^{\mathrm{a}, \mathrm{b}, \mathrm{c}, *}$, Regina Santos ${ }^{\mathrm{a}}$, Letícia M. Estevinho ${ }^{\mathrm{d}, \mathrm{e}}$, Ilda Caldeira, ${ }^{\mathrm{f}, \mathrm{g}}$

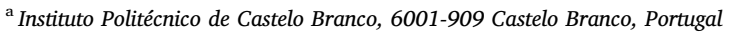 \\ ${ }^{\mathrm{b}}$ Centro de Biotecnologia de Plantas da Beira Interior, 6001-909 Castelo Branco, Portugal \\ ${ }^{c}$ CEF, Instituto Superior de Agronomia, Universidade de Lisboa, 1349-017 Lisboa, Portugal \\ d Centro de Investigação de Montanha (CIMO), Instituto Politécnico de Bragança, 5300-252 Bragança, Portugal \\ e Department of Biology and Biotechnology, Agricultural College of Bragança, Polytechnic Institute of Bragança, Campus Santa Apolónia, 5300-253 Bragança, Portugal \\ ${ }^{\mathrm{f}}$ INIAV, INIAV-Dois Portos, Quinta da Almoínha, 2565-191 Dois Portos, Portugal \\ ${ }^{\mathrm{g}}$ ICAAM - Instituto de Ciências Agrárias e Ambientais Mediterrânicas, Instituto de Investigação e Formação Avançada, Universidade de Évora, Núcleo da Mitra, 7000 \\ Évora, Portugal
}

\section{A R T I C L E I N F O}

\section{Keywords:}

Honey spirit

Online monitoring

Distillation process

RAMAN

\begin{abstract}
A B S T R A C T
Honey spirit is an alcoholic beverage produced by fermentation followed by distillation of the honey must, which has distinct organoleptic characteristics derived mostly from the raw material used. In order to accurately monitor the quality of the product throughout the distillation process (head, heart and tail stages), FT-RAMAN spectroscopy was applied. Dark honey, light honey and honey obtained following waxes' wash was used to produce honey spirit. The $\mathrm{pH}$, alcoholic strength, methanol content, acetaldehyde content, ethyl acetate content and higher alcohols content were evaluated during the distillation process. The FT-RAMAN technique was used to obtain spectral information for all fractions collected during beverage production. The results suggest that the honey spirit had good quality concerning the volatile composition and methanol was not detected in any sample. FT-RAMAN is promising for the online monitoring of the distillation process in order to improve the final quality of this beverage.
\end{abstract}

\section{Introduction}

Honey is a rich food containing a high amount of carbohydrates (60-82\%) (Anjos, Campos, Ruiz, \& Antunes, 2015; de la Fuente, RuizMatute, Valencia-Barrera, Sanz, \& Martínez Castro, 2011) mainly fructose and glucose, and other minor compounds (proteins, enzymes free amino acids, essential minerals, vitamins and polyphenols) (da Silva, Gauche, Gonzaga, Costa, \& Fett, 2016). The chemical composition and flavour of this natural product depends on its floral origin (Ceballos, Pino, Quijano-Celis, \& Dago, 2010; Cuevas-Glory, Pino, Santiago, \& Sauri-Duch, 2007).

The high concentration of carbohydrates may be converted into alcohol trough the yeast fermentation process; which, in adequate conditions, may lead to mead production (Vidrih \& Hribar, 2016). Little information is available in the literature regarding the characterization of honey spirit (Anjos, Frazão, \& Caldeira, 2017; Pino \& Fajardo, 2011). Pino and Fajardo (2011) performed an important study about the identification of volatile flavour compounds of spirits from unifloral honeys. In this study the authors identified that the most abundant classes of honey spirit volatile compounds were saturated alcohols, ethyl esters of saturated fatty acids and terpenes, and the author also identified some chemical markers for honey spirit produced with honey from different floral origin.

Honey spirit is obtained by honey fermentation (leading to mead production) and posterior distillation, following the recommended of the European legislation (Regulation EC No 110/2008). The resulting drink must be distilled at $<86 \%$ volume and must have a minimum alcoholic strength by volume of 35\%; ethyl alcohols and/or distillates of agricultural origin cannot be added and it must not be flavoured and may only contain added caramel as a mean to adapt colour and it may only be sweetened with honey.

Several honey spirits produced by Portuguese artisans were recently characterized (Anjos et al., 2017). In this study, alcohol strength varied between $37.4 \%$ and $53.0 \%$ while the methanol content was almost null for most of the samples. Regarding the sensory characteristics, the product was defined as fruity, floral and vegetative/herbaceous (orthonasal attributes) and smoky, sweet and bitter (gustatory attributes). On the other hand, as far as the authors know, no literature exists

\footnotetext{
* Corresponding author at: Instituto Politécnico de Castelo Branco, 6001-909 Castelo Branco, Portugal.

E-mail address: ofelia@ipcb.pt (O. Anjos).
} 
regarding the monitoring of the distillation process.

The information available from other distillated beverages indicates that the head fraction (fore-run part of a distillate) and the tail fraction (after-run part of a distillate) must be discarded since they may contain substantial amounts of toxic compounds, like methanol, or compounds that contribute negatively to sensory quality (Silva \& Malcata, 2002). The middle-run fraction is known as the heart and it is the part of the distillate used for the consumption, which contains the majority of the ethanol and the volatile compounds responsible for the aroma profile of the beverages (López-Vázquez, Herminia Bollaín, Berstsch, \& Orriols, 2010; Serafim et al., 2012; Silva \& Malcata, 2002). The distillate composition changes during the distillation process (Caldeira, Gomes, \& Botelho, 2018) (Serafim et al., 2012). Consequently, it is very important to develop analytical tools that allow this process to be monitored.

Several studies emphasised the applicability of spectroscopic techniques, namely FTIR, NIR and RAMAN, for the quality control of alcoholic beverages. However, their application on spirits is scarce. The RAMAN vibrational spectroscopic method has the potential to provide quickly answer concerning a huge number of chemical details of molecular structure, which makes this technique good for sample identification and quantification (Larkin, 2011). The RAMAN spectrum provides a chemical fingerprint of a single chemical substance or a mixture with specific characteristics. Concerning this ability, RAMAN spectroscopy have been used in several contexts, among which the determination of methanol content in alcoholic drinks (Vaskova, 2014); food product characterization and quantification (Anjos, Santos, Paixão, \& Estevinho, 2018) and real time monitoring of wine fermentation (Wang, Li, Ma, \& Liang, 2014). Also, Mendes, Oliveira, Suarez, and Rubim (2003) applied FT-Raman spectrometry to evaluate the ethanol content in cachaça and whisky. Kiefer and Cromwella (Kiefer \& Cromwell, 2017) demonstrate that Raman spectroscopy is suitable for analysing the authenticity of whisky. Song et al. (2017) evaluated the potentiality of RAMAN spectroscopy to determine the ethanol and methanol content in distilled spirits.

This work aims to study the discontinuous distillation process of mead by controlling the quality of the distillate by classical chemical analyses and for first time by applying RAMAN spectroscopic techniques for online monitoring the distillation process.

\section{Material and methods}

\subsection{Experimental design and sampling}

Three different meads produced with dark honey (HD), light honey (HL) and honey from waxes wash (HW) were distilled. The mead samples have been previously characterized (Table 1): the three had similar characteristics, with an average $\mathrm{pH}$ of 3.43 , a titrable acidity of $3.9 \mathrm{~g} / \mathrm{L}$ of tartaric acid; a volatile acidity of $0.67 \mathrm{~g} / \mathrm{L}$ of acetic acid; a $\mathrm{SO}_{2}$ concentration of $31.1 \mathrm{mg} / \mathrm{L}$ and an alcoholic strength of $12 \%$. However, the mead produced with dark honey had higher values of reducing sugars $(35 \mathrm{~g} / \mathrm{L}$ while the value obtained for the other meads

Table 1

Results of the analytical parameters measured in the meads.

\begin{tabular}{llll}
\hline Analytical parameters & $\begin{array}{l}\text { Dark } \\
\text { honey } \\
\text { (HD) }\end{array}$ & $\begin{array}{l}\text { Light } \\
\text { honey } \\
\text { (HL) }\end{array}$ & $\begin{array}{l}\text { Honey from waxes } \\
\text { wash (HW) }\end{array}$ \\
\hline pH & 3.44 & 3.35 & 3.50 \\
Titrable acidity (g/L of tartaric & 3.75 & 3.64 & 4.35 \\
$\quad$ acid) & 0.57 & 0.69 & 0.75 \\
$\begin{array}{l}\text { Volatile acidity (g/L of acetic } \\
\text { acid) }\end{array}$ & 31.8 & 30.7 & 30.7 \\
$\begin{array}{l}\text { SO2 concentration (mg/L) } \\
\text { Alcoholic strength (\%) }\end{array}$ & 10.5 & 12.7 & $\begin{array}{l}12 \\
\text { Reducing sugars (g/L) }\end{array}$ \\
$\quad 35.2$ & 23.5 & 24.1 \\
\hline
\end{tabular}

was $24 \mathrm{~g} / \mathrm{L})$.

The experimental design followed a cross two-factorial hierarchy: raw material with three levels (HD, HL and HW); distillation time with 6 levels (from $0.5 \mathrm{~min}$ to $2.8 \mathrm{~min}$ ); distillation volume with 6 levels (from $100 \mathrm{~mL}$ to $700 \mathrm{~mL}$ ). For the distillation process characterization, two distillations from each raw material were performed.

The distillation process was carried out using a "Charentais" copper alembic with $10 \mathrm{~L}$ of volume in which $3.5 \mathrm{~L}$ of mead was placed. The alembic was heated by using a heating plate (Thermolyne Cimarec ${ }^{\circledR} 3$ ). When the temperature of mead raises the $91{ }^{\circ} \mathrm{C}$ the distillation process starts and distillate begins to drop on the condenser, and the heating plate was adjusted for a drop out flow of the distillate. To establish the distillation curves fractions of $100 \mathrm{~mL}$ were successively collected over the time.

\subsection{Chemical analysis}

Each fraction of spirit $(100 \mathrm{~mL})$ collected over the distillation process was submitted to the following analyses: $\mathrm{pH}$, alcoholic strength, methanol content, acetaldehyde content, ethyl acetate content and higher alcohols content. The $\mathrm{pH}$ was determined using a potentiometer (Crison), according to the official method (OIV, 2014). The alcohol strength was determined by distillation followed by electronic densimetry (OIV, 2014), using an electronic densimeter Model 5000 DMA brand Anton Paar. The results are represented as volumetric percentage of ethanol in the beverage and resulting from the arithmetic mean of two replicate analyses.

The methanol, acetaldehyde, ethyl acetate and higher alcohols content, of each sample were analysed by gas chromatography-flame ionization detection (GC-FID) according the methodology described and validated by Luís, Mota, Anjos, and Caldeira (2011).

The compounds concentrations were determined by direct injection of the distillate. Prior to injection, $1 \mathrm{~mL}$ of internal standard solution (5methyl-2-pentanol) was added to $10 \mathrm{~mL}$ of each sample (distillate of honey spirit drink). The GC-FID analysis was carried out using a Focus GC gas chromatograph (Thermo Scientific, USA) equipped with a flame ionization detector-FID $\left(250^{\circ} \mathrm{C}\right)$ and a fused silica capillary column of polyethylene glycol (DB-WAX, JW Scientific, Folsom, CA, USA), $60 \mathrm{~m}$ length, $0.32 \mathrm{~mm}$ i.d., $0.25 \mu \mathrm{m}$ film thickness. The carrier gas was hydrogen $\left(3.40 \mathrm{~cm}^{3} \cdot \mathrm{min}^{-1}\right)$. The samples were loaded $(\sim 1 \mu \mathrm{L})$ on the injector $\left(200^{\circ} \mathrm{C}\right)$ in split mode (split ratio $\left.1: 6\right)$. The oven temperature program was $35^{\circ} \mathrm{C}$ (for $8 \mathrm{~min}$ ), then increased at $10^{\circ} \mathrm{C} \cdot \mathrm{min}^{-1}$ to $200^{\circ} \mathrm{C}$ and held at this temperature for a further $1 \mathrm{~min}$. The results were expressed in grams per litre.

\subsection{FT-RAMAN spectral acquisition}

The spectral information of the spirits samples was obtaining using a FT-Raman, with 100 scans per spectrum at a spectral resolution of $8 \mathrm{~cm}^{-1}$, with a scanner velocity of $5 \mathrm{kHz}$ in the wavenumber range from 3500 to $70 \mathrm{~cm}^{-1}$. The FT-Raman spectrometer (BRUKER, MultiRAM) was equipped with a $180^{\circ}$ high-throughput collecting lens, a ultra-high sensitivity Liquid Nitrogen cooled Ge Diode detector, an integrated $1064 \mathrm{~nm}$, diode pumped, Nd:YAG laser with a maximum output power of $500 \mathrm{~mW}$.

The system was operated using the OPUS software provided by the manufacturer. Two independent measurements were performed for each sample in a quartz cell of $5 \mathrm{~mm}$ of optic space with the opposite face mirrored. The spectra were collected at a constant room temperature of $22^{\circ} \mathrm{C}$.

\subsection{Data analysis}

Analysis of variance (ANOVA) was performed for the chemical parameters assessed. For each significant factor or interaction, the variance percentage was calculated and a Schefée post-hoc test with 



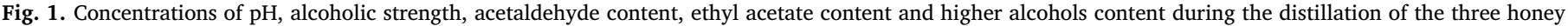
spirits produced. 
95\% confidence was performed. In the results, an equal letter (a) is attributed to mean values that are not statistically different for the different modalities. All the calculations were performed using Statgraphics from Statsoft (vs 7.09).

Principal component analyses (PCA) of spectral information were performed using the Unscrambler ${ }^{\circledR} \mathrm{X}$, version: 10.5.46461.632 (CAMO Software AS, Oslo, Norway) and OPUS ${ }^{\circledR}$, version: 7.5.18 (Bruker Optik, Germany). For PCA spectral analysis several pre-treated were tested in order to identify the best one, namely: standard normal variate (SNV), multiplicative scatter correction (MSC), normalize, centred and scaled, first derived Savitzky-Golay (1st derived), second derived Savitzky-Golay (2nd derived) and some combinations of 2 pre-treatments.

\section{Results and discussion}

The results for the distillation fractions collected during the distillation process of the different meads are presented in Fig. 1. The information available in the literature regarding honey spirit is scarce (Anjos et al., 2017; Roldán, van Muiswinkel, Lasanta, Palacios, \& Caro, 2011); therefore, the hereby reported results were compared with those obtained throughout the distillation processes of other food products and beverages.

The $\mathrm{pH}$ value of the distillates during the distillation time is quite similar between the different raw-materials (Fig. 1) and decreased with the distillation time. A similar decreasing pattern was described by other authors for other spirits (Serafim et al., 2012). The pH values ranged between 3.8 (last fraction of HW spirit) and 5.7 (fraction 1 of LH spirit). Concerning the statistical analysis, only the distillation time is a factor highly significant that explains $82 \%$ of the total variation (Table 2). The alcohol strength of this kind of beverages decrease during the distillation progress, as expected, and varied depending on the raw material used ( $92 \%$ of the total variation, Table 2$)$. At the beginning of the distillation the alcohol strength is higher which could be indicate a higher volume of distillate in the process.

Almost all samples and all fractions had no measurable methanol content. Very low concentration of methanol was found for HL spirit $(<0.031 \mathrm{~g} / \mathrm{L})$. In the fermentation process of some honey with lower mineral and phenol content, sometimes the presence of pollen is necessary to help the fermentation process (Roldán et al., 2011).

Acetaldehyde is a toxic metabolite (depending of the concentration) formed by alcohol metabolism during the fermentation of raw materials (Silva \& Xavier, 1998). However, according to the same author, the sensory descriptors for acetaldehyde could range from nutty and sherry (lower concentration) to overripe bruised apples (higher

Table 2

Variance percentage of each factor based on ANOVA of the analytical parameters evaluated in the honey spirit.

\begin{tabular}{|c|c|c|c|c|}
\hline \multirow[t]{2}{*}{ Analytical parameters } & \multicolumn{4}{|c|}{ Variance origin } \\
\hline & $\begin{array}{l}\text { Raw } \\
\text { material } \\
(\mathrm{Rm})\end{array}$ & Fraction $(\mathrm{F})$ & $\mathrm{RmxF}$ & Residual \\
\hline $\mathrm{pH}$ & (NS) & $81.8\left(^{* * *}\right)$ & (NS) & 18.2 \\
\hline Alcohol strength (\% v/v) & $6.0(* * *)$ & $92.3(* * *)$ & $1.1(* *)$ & 0.6 \\
\hline Acetaldehyde $(\mathrm{g} / \mathrm{L})$ & $7.5(* * *)$ & $74.8\left(^{* * * *}\right)$ & $15.9^{(* * *)}$ & 1.7 \\
\hline Ethyl acetate $(\mathrm{g} / \mathrm{L})$ & $1.1(* * *)$ & $89.5\left(^{(* * *)}\right)$ & $8.6(* * *)$ & 0.7 \\
\hline Propan-1-ol (g/L) & $8.3(* * *)$ & $85.5(* * *)$ & (NS) & 6.2 \\
\hline 2-Methylpropan-1-ol (g/L) & $10.1(* * *)$ & $84.3(* * *)$ & $2.7(*)$ & 3.0 \\
\hline Butan-1-ol (g/L) & (NS) & (NS) & (NS) & (NS) \\
\hline $2+3$-Methylbutan-1-ol (g/L) & $9.5(* * *)$ & $88.4\left(^{* * *}\right)$ & $1.7\left({ }^{* * *}\right)$ & 0.4 \\
\hline
\end{tabular}

NS, $P>0.05$.

* $0.01<P<0.05$.

** $0.001<P<0.01$.

*** $P<0.001$ concentration).

Acetaldehyde and ethyl acetate content decreased greatly during the distillation processes. This factor is responsible for $75 \%$ and $90 \%$ of the total variance, respectively (Table 2). This variation is more significant in the first three factions and became quite null in the next ones that was in accordance with the results of other authors (Apostolopoulou, Flouros, Demertzis, \& Akrida-Demertzi, 2005).

In the first faction of the distillates the level of acetaldehyde is significant higher for the HD spirit $(1.337 \mathrm{~g} / \mathrm{L})$ and represent $7 \%$ of the total variance (ANOVA Results). However, acetaldehyde values observed in the first's fraction of honey spirit are lower than those obtained in other spirits, which is another advantage of this beverage. Soufleros, Mygdalia, and Natskoulis (2005), analysed traditional Greek arbutus spirit from local producers, and reported values for ethyl acetate between 104.5 and $1630.0 \mathrm{~g} / \mathrm{hL}$ P.A. and for acetaldehyde between 34.5 and $270.0 \mathrm{~g} / \mathrm{hL}$ P.A.. Honey spirits in our study present similar or lower contents of these two compounds and are similar to those reported for the other authors that analysed honey spirit (Anjos et al., 2017; Roldán et al., 2011).

Higher alcohols are the group of compounds with the highest concentration in these kind of beverages which contribute to the flavouring aroma and are important concerning the sensory product quality (Caldeira, Anjos, Belchior, \& Canas, 2017; Lukić, Miličević, Tomas, Radeka, \& Peršurić, 2012). According to the same authors, higher concentrations occur in the first fraction of the distillates and the levels of these compounds could be influenced by raw materials, processing factors, fermentation conditions, distillation techniques, and others.

Distilled spirits are characterized by several compounds (present in relatively large amounts) which arise during the fermentation process, mainly fusel alcohols, fatty acids and esters. According to MacNamara et al. (Mac Namara, Leardi, \& Sabuneti, 2005) the most abundant secondary compounds present in distilled spirits are the fusel alcohols as well fatty acid esters, together with acetaldehyde and its acetals.

The values of these compounds decrease also during the distillation process and for the different compounds analysed (propan-1-ol; 2-methylpropan-1-ol, butan-1-ol and 2+3-methylbutan-1-ol). For these compounds the factor fractions are highly representative and explain $>84 \%$ of the total variation (Table 2). However, in this case the raw material is also highly significant and explains between $8 \%$ and $10 \%$ of the total variation (Table 2 ).

Since is difficult to access the correct point were the tails begin in real time in a distillery, the use of a portable spectrometer could be used. In this work was evaluated the potentiality of the RAMAN methodology for this purpose.

In Fig. 2 it is presented three representative spectra of the honey spirit for the fractions considered (head, heart and tails).

The observed spectra (Fig. 2) are similar to those reported for other alcoholic beverages like whisky and cachaça (Mendes et al., 2003; Vaskova, 2014), gin, apricot and plum brandy (Vaskova, 2014) and tequila (Frausto-Reyes, Medina-Gutiérrez, Sato-Berrú, \& Sahagún, 2005).

The peaks at 2800 to $3050 \mathrm{~cm}^{-1}$ correspond to the $\mathrm{CH}$ stretching modes (Mendes et al., 2003). This region is characteristic of the ethanol, methanol and other organic species (Numata, Iida, \& Tanaka, 2011), being an important region to discriminate the different raw materials and to differentiate the steps in the destination process (Fig. 1, loading representation). As it may be observed in Fig. 2 this region decreased from head to tail.

According to the study performed by Mendes et al. (2003) the more important region to quantify ethanol (the main compound in honey spirit) is from 779 to $1331 \mathrm{~cm}^{-1}$ and between 2774 and $3518 \mathrm{~cm}^{-1}$. Nonetheless, in our case the region between 3500 and $3000 \mathrm{~cm}^{-1}(-\mathrm{OH}$ stretching) does not contribute to the discrimination between distillation stages (Figs. 2 and 3).

The small peak at $2883 \mathrm{~cm}^{-1}$ is assigned by the in-phase stretch of methyl group $\left(-\mathrm{CH}_{3}\right)$. 


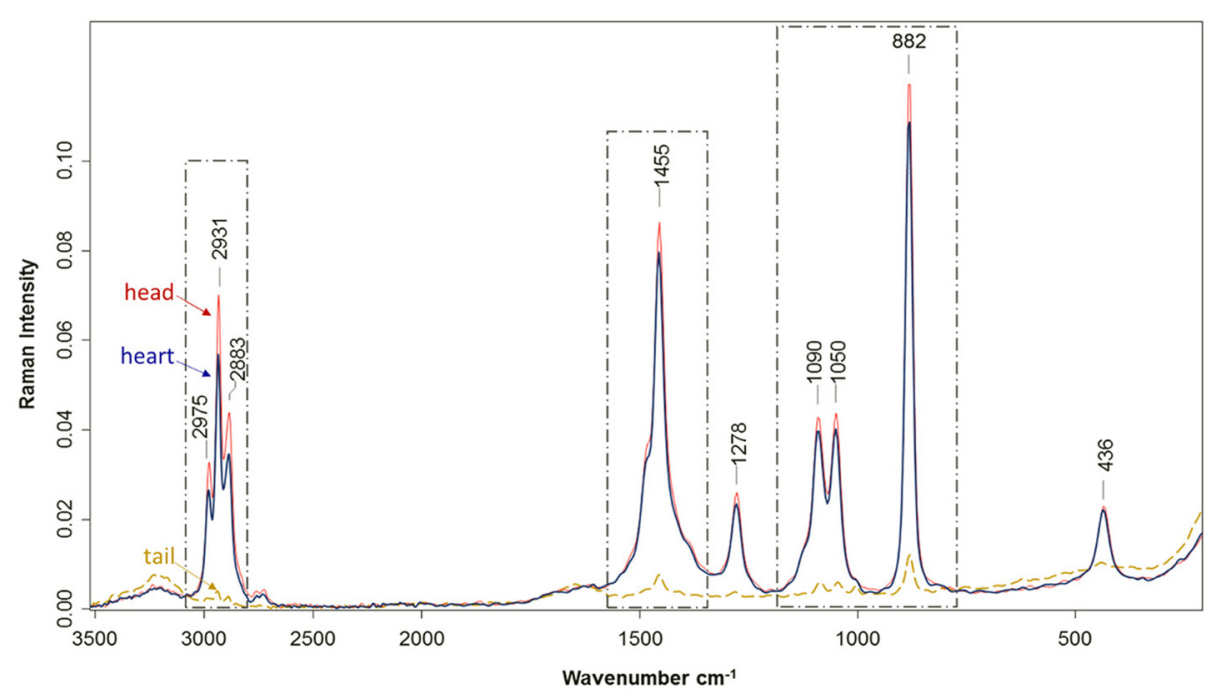

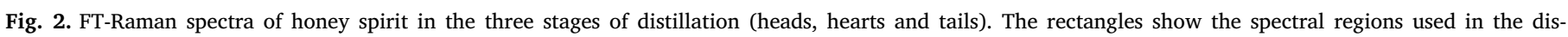
crimination analysis.

FT RAMAN spectra was characterized by bands in three regions of 2700 to $3050 \mathrm{~cm}^{-1}$, from 1600 to $750 \mathrm{~cm}^{-1}$ and a small peak at $436 \mathrm{~cm}^{-1}$.

The peaks observed at 2975, 2931 and $2883 \mathrm{~cm}^{-1}$ (Fig. 2) are assigned to the $\mathrm{CH}_{2}$ and $\mathrm{CH}_{3}$ stretching of the ethanol and are influenced by the other substances in the honey beverage (Picard, Daniel, Montagnac, \& Oger, 2007; Vaskova, 2014). This region is also influenced by the methanol content in the alcoholic beverages. The peak at $1455 \mathrm{~cm}^{-1}$ corresponds to $\mathrm{C}-\mathrm{OH}$ bending, very important for the different alcohol content present in the spirits (Coussan, Alikhani, Perchard, \& Zheng, 2000; Mendes et al., 2003) and as it can observed in Fig. 2 this peak decrease from head to tail like the alcohol strength (Fig. 1).

The spectral region observed in Fig. 2, from 1300 to $1050 \mathrm{~cm}^{-1}$ regards in-plane movement of the ring carbons and the substituents and is an important region for alcohols, ethers, esters, carboxylic acids, and anhydrides (Larkin, 2011) characterization. These compounds are also characterized by $\mathrm{C}-\mathrm{O}$ stretch vibrations in the region $1200-750 \mathrm{~cm}^{-1}$. The bending band at $1278 \mathrm{~cm}^{-1}$ corresponds to the in-phase $\mathrm{CH}_{2}$ twist and wagging (Coussan et al., 2000). Also, the C-O stretch of carboxylic acids is characterized by highly variable intensity Raman bands in these regions (Larkin, 2011).

The peaks at 1050 and $1090 \mathrm{~cm}^{-1}$ corresponded with an asymmetric C-C-O stretch and $\mathrm{CH}_{3}$ rocking respectively (Picard et al., 2007).

Primary and Secondary alcohols are characterized by a strong Raman band at $882 \mathrm{~cm}^{-1}$ (Fig. 2). that corresponds to an asymmetric CC-O stretch (Vaskova, 2014). This band has been used to quantify the ethanol content in the alcoholic beverages (Cleveland et al., 2007).

The peak at $436 \mathrm{~cm}^{-1}$ (Fig. 2) could be related to skeletal vibrational modes, namely $\mathrm{C}-\mathrm{C}-\mathrm{O}$ and $\mathrm{C}-\mathrm{C}-\mathrm{C}, \mathrm{C}-\mathrm{O}$ and $\mathrm{C}-\mathrm{C}$ as proposed by Korolevich, Zhbankov, and Sivchik (1990).
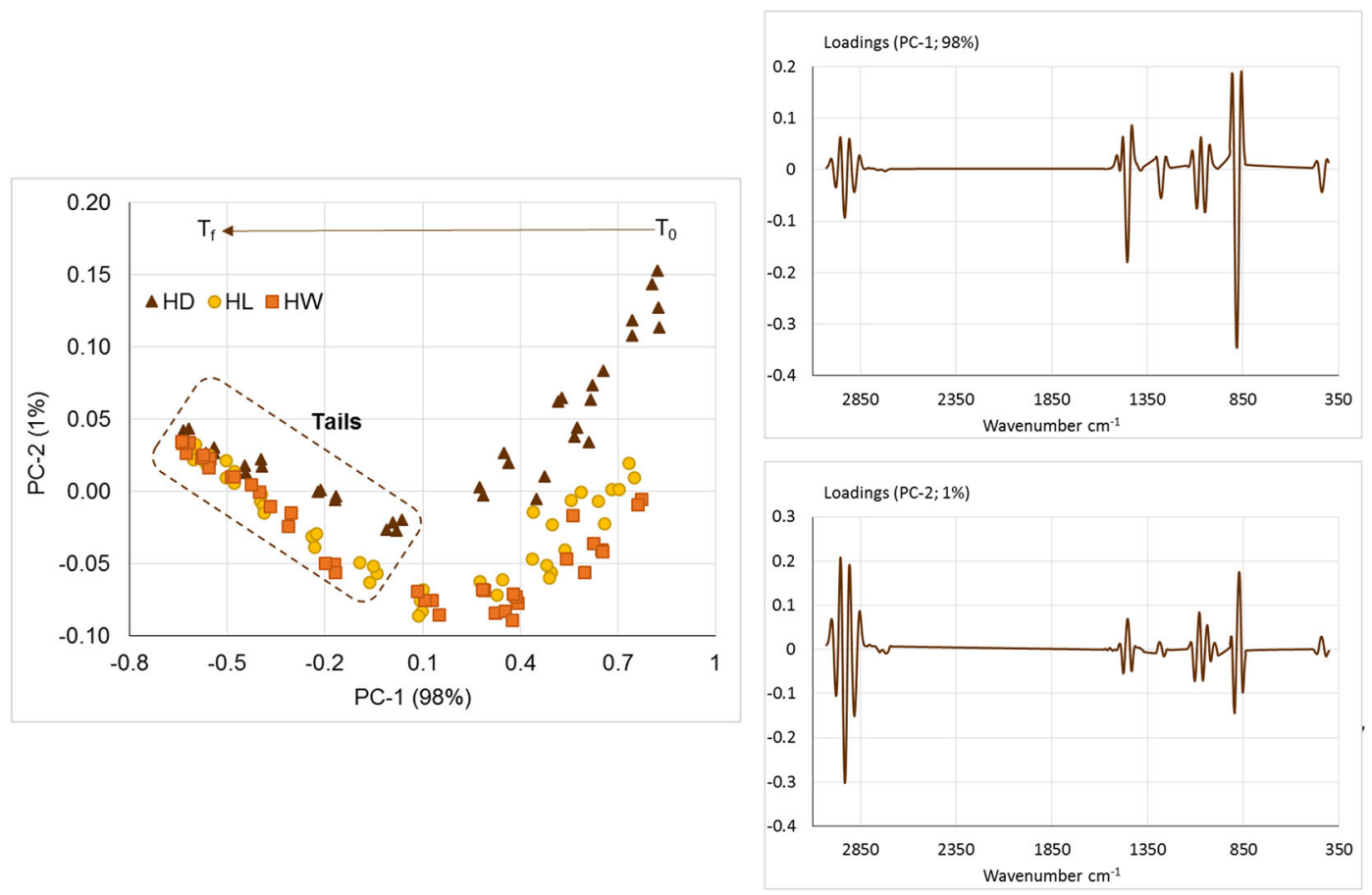

Fig. 3. Principal component analysis for all fraction of the distillation process of the honey spirit from 3 different raw materials and respective loading representation using 2 nd derivative as pre-process. $\mathrm{T}_{0}$ - start of the distillation process; $\mathrm{T}_{\mathrm{f}}-$ end of the distillation process. 

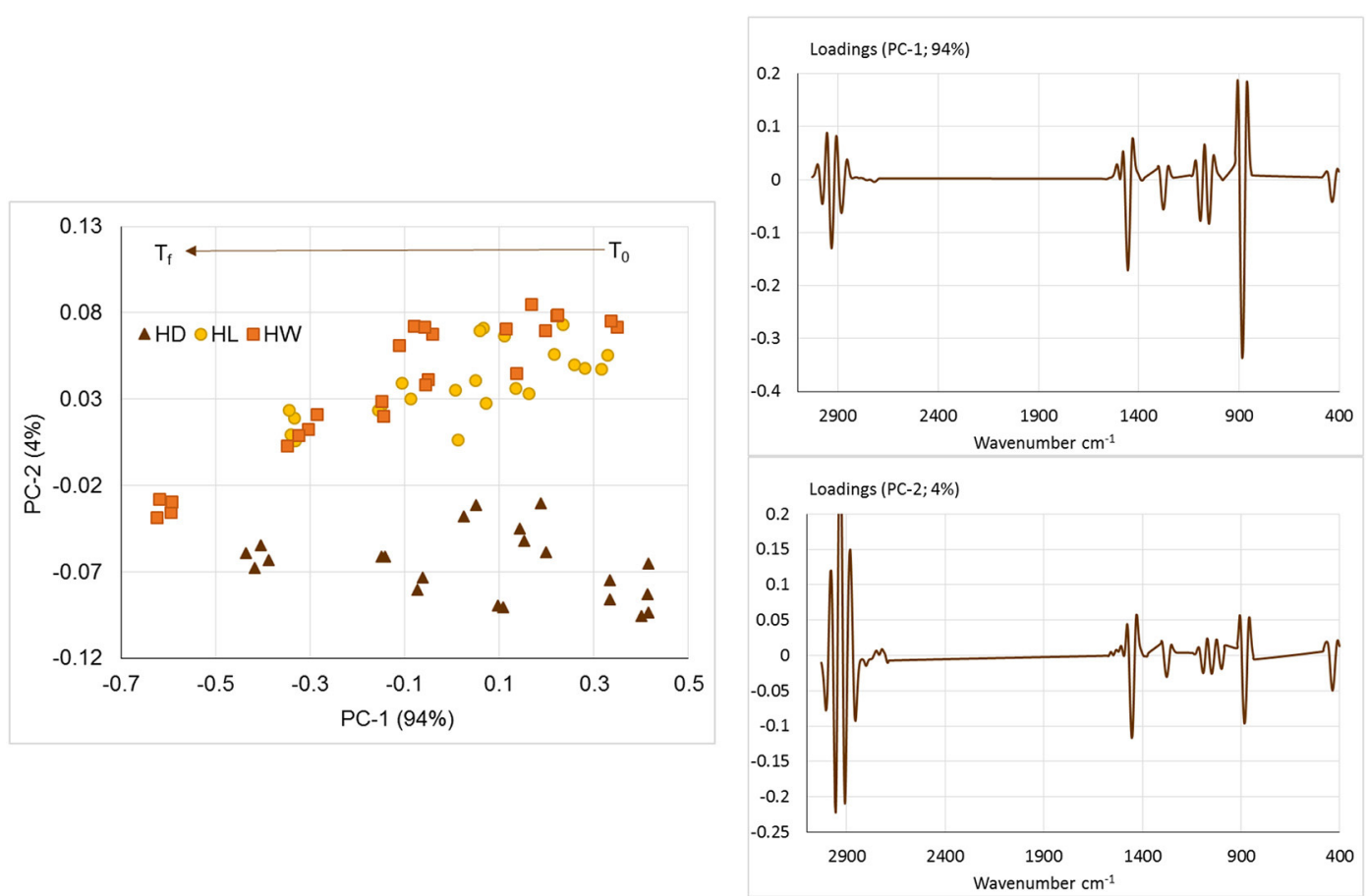

Fig. 4. Principal component analysis for the fraction selected as heart of the distillation process of the honey spirit from 3 different raw materials and respective loading representation using 2 nd derivative as pre-process. $T_{0}$ - start of the distillation process; $\mathrm{T}_{\mathrm{f}}-$ end of the heart phase of distillation process.

Principal component analysis (PCA) was used to discriminate the differences between fractions and samples, in terms of qualitative analysis. The PCA was performed in the spectral region from $3000 \mathrm{~cm}^{-1}$ to $350 \mathrm{~cm}^{-1}$ after testing for several pre-processes. The 1st derivative with 17 smoothing points and the 2nd derivative with 13 points smoothing were the pre-processes that provided more relevant information. As the first principal components explained $>90 \%$ of the dataset variance, further observations were based on the PC-1 and PC-2 scores (Fig. 2). In the following figures are presented only the results for 2nd derivative since it seems more accurate that the 1st derivative (Fig. 2). Afterwards, with the selected region a final PCA was performed to discriminate the evolution of quality of the distillation processes. For the quantitative analysis only six fractions were made yet more samples had been collected, in tails fraction for spectroscopic analysis.

The PCA of spirits fraction (Fig. 3) reveals that tails from the honey distillates can be clearly separated from the heart fraction and a differentiation between HD and spirit from the others is possible. Regarding HD heart spirits (Fig. 4) two clusters can also be perceived.

According the loading graphic of PC1 (Figs. 3 and 4) of honey spirit, is clearly plotted that the for fraction separation during the distillation process, the region from $1000 \mathrm{~cm}^{-1}$ to $800 \mathrm{~cm}^{-1}$ was the more important. However, the other two regions also provide significant information. Indeed, to discriminate the different raw material, the region between $3000 \mathrm{~cm}^{-1}$ to $2800 \mathrm{~cm}^{-1}$ deliver more relevant information. These two regions were also identified as important for quality control of grape-derived spirits using FTIR-ATR spectroscopy (Anjos, Santos, Estevinho, \& Caldeira, 2016).

Selected regions using in the PCA can be used to discriminate the monitoring of distillation process. In this case, hence the head fraction does not exist for honey spirit, the first fraction could be used in the final lot.

RAMAN spectroscopy is a good technique to monitor honey spirits quality during the distillation process and is promising to detect slight adulterations. For this purpose, PCA can be used for identification analysis thus clarifying whether or not a suspect sample belongs to a specific phase of the distillation process.

\section{Conclusions}

Honey spirit is an alcoholic beverage with a characteristic composition, depending on the raw material. One of the more interesting characteristic is the absence of methanol and head fraction. The obtained results show that the use of Raman spectroscopy and PCA analysis can be a helpful method to discriminate the different distillation phases in honey spirit. In addition, this methodology may be applied to identify different raw materials in this kind of alcoholic beverages. The potentiality of FT-RAMAN may be further explored for future applications in other spirit beverages.

\section{Declaration of competing interest}

The authors declare that they have no known competing financial interests or personal relationships that could have appeared to influence the work reported in this paper.

\section{Acknowledgement}

This research was funded by Centro de Estudos Florestais a research unit funded by FCT (UID/AGR/00239/2019); Centro de Investigação de Montanha (CIMO), Instituto Politécnico de Bragança, and by ICAAM a research unit funded by FCT - Foundation for Science and Technology, under the Project UID/AGR/00115/2019.

\section{References}

Anjos, O., Campos, M. G., Ruiz, P. C., \& Antunes, P. (2015). Application of FTIR-ATR spectroscopy to the quantification of sugar in honey. Food Chemistry, 169, 218-223. https://doi.org/10.1016/j.foodchem.2014.07.138.

Anjos, O., Frazão, D., \& Caldeira, I. (2017). Physicochemical and sensorial characterization of honey spirits. Foods, 6(8), 58. https://doi.org/10.3390/foods6080058.

Anjos, O., Santos, A. J. A., Estevinho, L. M., \& Caldeira, I. (2016). FTIR-ATR spectroscopy applied to quality control of grape-derived spirits. Food Chemistry, 205, 28-35. https://doi.org/10.1016/j.foodchem.2016.02.128.

Anjos, O., Santos, A. J. A., Paixão, V., \& Estevinho, L. M. (2018). Physicochemical characterization of Lavandula spp. honey with FT-Raman spectroscopy. Talanta, 178, 43-48. https://doi.org/10.1016/j.talanta.2017.08.099.

Apostolopoulou, A. A., Flouros, A. I., Demertzis, P. G., \& Akrida-Demertzi, K. (2005). 
Differences in concentration of principal volatile constituents in traditional Greek distillates. Food Control, 16(2), 157-164. https://doi.org/10.1016/j.foodcont.2004. 01.005.

Caldeira, I., Anjos, O., Belchior, A. P., \& Canas, S. (2017). Sensory impact of alternative ageing technology for the production of wine brandies. Ciência e Técnica Vitivinícola, 32(1), 12-22. https://doi.org/10.1051/ctv/20173201012.

Caldeira, I., Gomes, F., \& Botelho, G. (2018). Arbutus unedo L. Spirit: Does the water addition before fermentation matters? INCREaSE (pp. 206-215). Cham: Springer International Publishing. https://doi.org/10.1007/978-3-319-70272-8 16.

Ceballos, L., Pino, J. A., Quijano-Celis, C. E., \& Dago, A. (2010). Optimization OF A HSSPME/GC-MS method for determination of volatile compounds in some cuban unifloral honeys. Journal of Food Quality, 33(4), 507-528. https://doi.org/10.1111/j. 1745-4557.2010.00330.x

Cleveland, D., Carlson, M., Hudspeth, E. D., Quattrochi, L. E., Batchler, K. L., Balram, S. A., ... Michel, R. G. (2007). Raman spectroscopy for the undergraduate teaching laboratory: Quantification of ethanol concentration in consumer alcoholic beverages and qualitative identification of marine diesels using a miniature Raman spectrometer. Spectroscopy Letters, 40(6), 903-924. https://doi.org/10.1080/ 00387010701525638.

Coussan, S., Alikhani, M. E., Perchard, J. P., \& Zheng, W. Q. (2000). Infrared-induced isomerization of ethanol dimers trapped in argon and nitrogen matrices: Monochromatic irradiation experiments and DFT calculations. The Journal of Physical Chemistry A, 104(23), 5475-5483. https://doi.org/10.1021/jp0001283.

Cuevas-Glory, L. F., Pino, J. A., Santiago, L. S., \& Sauri-Duch, E. (2007). A review of volatile analytical methods for determining the botanical origin of honey. Food Chemistry, 103(3), 1032-1043. https://doi.org/10.1016/j.foodchem.2006.07.068.

da Silva, P. M., Gauche, C., Gonzaga, L. V., Costa, A. C. O., \& Fett, R. (2016). Honey: Chemical composition, stability and authenticity. Food Chemistry, 196, 309-323. https://doi.org/10.1016/j.foodchem.2015.09.051.

de la Fuente, E., Ruiz-Matute, A. I., Valencia-Barrera, R. M., Sanz, J., \& Martínez Castro, I. (2011). Carbohydrate composition of Spanish unifloral honeys. Food Chemistry, 129(4), 1483-1489. https://doi.org/10.1016/j.foodchem.2011.05.121.

Frausto-Reyes, C., Medina-Gutiérrez, C., Sato-Berrú, R., \& Sahagún, L. R. (2005). Qualitative study of ethanol content in tequilas by Raman spectroscopy and principal component analysis. Spectrochimica Acta Part A: Molecular and Biomolecular Spectroscopy, 61(11-12), 2657-2662. https://doi.org/10.1016/j.saa.2004.10.008.

Kiefer, J., \& Cromwell, A. L. (2017). Analysis of single malt scotch whisky using Raman spectroscopy. Analytical Methods, 9(3), 511-518. https://doi.org/10.1039/ C6AY02907H.

Korolevich, M. V., Zhbankov, R. G., \& Sivchik, V. V. (1990). Calculation of absorption band frequencies and intensities in the IR spectrum of $\alpha$-d-glucose in a cluster. Journal of Molecular Structure, 220, 301-313. https://doi.org/10.1016/00222860(90)80120-9.

Larkin, P. (2011). Infrared and Raman spectroscopy: Principles and spectral interpretation. Elsevier.

López-Vázquez, C., Herminia Bollaín, M., Berstsch, K., \& Orriols, I. (2010). Fast determination of principal volatile compounds in distilled spirits. Food Control, 21(11), 1436-1441. https://doi.org/10.1016/j.foodcont.2010.03.008.

Luís, A., Mota, D., Anjos, O., \& Caldeira, I. (2011). Single-laboratory validation of determination of acetaldehyde, ethyl acetate, methanol and fusel alcohols in wine spirits, brandies and grape marc spirits using GC-FID. Ciência e Técnica Vitivinícola, 26(2), 69-76.

Lukić, I., Miličević, B., Tomas, S., Radeka, S., \& Peršurić, Đ. (2012). Relationship between volatile aroma compounds and sensory quality of fresh grape marc distillates. Journal of the Institute of Brewing, 118(3), 285-294. https://doi.org/10.1002/jib.39.

Mac Namara, K., Leardi, R., \& Sabuneti, A. (2005). Fast GC analysis of major volatile compounds in distilled alcoholic beverages. Analytica Chimica Acta, 542(2), 260-267. https://doi.org/10.1016/j.aca.2005.03.046.

Mendes, L. S., Oliveira, F. C. C., Suarez, P. A. Z., \& Rubim, J. C. (2003). Determination of ethanol in fuel ethanol and beverages by Fourier transform (FT)-near infrared and FTRaman spectrometries. Analytica Chimica Acta, 493(2), 219-231. https://doi.org/10. 1016/S0003-2670(03)00870-5.

Numata, Y., Iida, Y., \& Tanaka, H. (2011). Quantitative analysis of alcohol-water binary solutions using Raman spectroscopy. Journal of Quantitative Spectroscopy and Radiative Transfer, 112(6), 1043-1049. https://doi.org/10.1016/j.jqsrt.2011.01.005.

OIV (2014). Compendium of international methods of analysis of spirituous beverages of vitivinicultural origin. (Paris).

Picard, A., Daniel, I., Montagnac, G., \& Oger, P. (2007). In situ monitoring by quantitative Raman spectroscopy of alcoholic fermentation by Saccharomyces cerevisiae under high pressure. Extremophiles, 11(3), 445-452. https://doi.org/10.1007/s00792-0060054-x.

Pino, J. A., \& Fajardo, M. (2011). Volatile composition and key flavour compounds of spirits from unifloral honeys. International Journal of Food Science \& Technology, 46(5), 994-1000. https://doi.org/10.1111/j.1365-2621.2011.02586.x.

Roldán, A., van Muiswinkel, G. C. J., Lasanta, C., Palacios, V., \& Caro, I. (2011). Influence of pollen addition on mead elaboration: Physicochemical and sensory characteristics. Food Chemistry, 126(2), 574-582. https://doi.org/10.1016/j.foodchem.2010.11.045.

Serafim, F. A. T., Galinaro, C. A., Da Silva, A. A., Buchviser, S. F., Do Nascimento, E. S. P., Novaes, F. V., \& Franco, D. W. (2012). Quantitative chemical profile and multivariate statistical analysis of alembic distilled sugarcane spirit fractions. Journal of the Brazilian Chemical Society, 23(8), 1506-1514. https://doi.org/10.1590/S010350532012005000015.

Silva, M. L., \& Malcata, F. X. (2002). Effects of time of grape pomace fermentation and distillation cuts on the chemical composition of grape marcs. Zeitschrift Fur Lebensmittel-Untersuchung Und-Forschung A-Food Research \& Technologyr Lebensmitteluntersuchung Und -Forschung A, 208(2), 134-143. https://doi.org/10. $1007 / \mathrm{s} 002170050390$.

Silva, M. L., \& Xavier, M. F. (1998). Relationships between storage conditions of grape pomace and volatile composition of spirits obtained therefrom. American Journal of Enology and Viticulture, 49, 56-64.

Song, L., Liu, L., Yang, Y., Xi, J., Guo, Q., \& Zhu, X. (2017). Online detection of distilled spirit quality based on laser Raman spectroscopy. Journal of the Institute of Brewing, 123(1), 121-129. https://doi.org/10.1002/jib.399.

Soufleros, E. H., Mygdalia, S. A., \& Natskoulis, P. (2005). Production process and characterization of the traditional Greek fruit distillate "Koumaro" by aromatic and mineral composition. Journal of Food Composition and Analysis, 18(7), 699-716. https:// doi.org/10.1016/j.jfca.2004.06.010.

Vaskova, H. (2014). Spectroscopic determination of methanol content in alcoholic drinks. International Journal of Biology and Biomedical Engineering, 8.

Vidrih, R., \& Hribar, J. (2016). Mead: The oldest alcoholic beverage. Traditional foods (pp. 325-338). Boston, MA: Springer US. https://doi.org/10.1007/978-1-4899-76482_26.

Wang, Q., Li, Z., Ma, Z., \& Liang, L. (2014). Real time monitoring of multiple components in wine fermentation using an on-line auto-calibration Raman spectroscopy. Sensors and Actuators B: Chemical, 202, 426-432. https://doi.org/10.1016/j.snb.2014.05. 109. 